\title{
RELATIONSHIP BETWEEN BODY MASS INDEX (BMI) AND SURGICAL COMPLICATIONS AFTER BREAST ONCOLOGICAL SURGERY
}

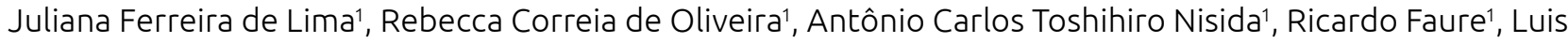
Henrique Gebrim

${ }^{1}$ Centro de Referência da Saúde da Mulher, Hospital Pérola Byington - São Paulo (SP), Brazil.

Introduction: Obesity is a multifactorial chronic disease that can predispose to several comorbidities, including breast cancer. The Department of Health estimates the number of overweight people in Brazil is 65\%. The relationship between weight and height (BMI, Body Mass Index) has been used by WHO to assess the degree of obesity in the population. Breast cancer is responsible for more than 8,000 deaths each year in Brazil. Despite advances in systemic treatment, surgery is one of the main treatments used, and obesity is a relevant factor that worsens the oncological prognosis and is predictive of perioperative complications. Objectives: The aim of this study is to assess the relationship between obesity and surgical complications in 5,657 breast cancer patients undergoing surgical treatment (conservative or radical) at Pérola Byington Hospital. Methods: A retrospective, cross-sectional study was carried out with 5,657 patients undergoing surgical treatment (conservative or radical) by the Braziliann Unified Health System (SUS) at the Women's Health Reference Center at Hospital Pérola Byington from January 2011 to December 2019. Data were collected from the medical records of the institution. The patients were divided into six groups according to BMI=W/H2 (<18.5 underweight, between 18.5 and 24.9 normal, 25 to 29.9 overweight, between 30 and 34.9 obese, 35 to 39.9 severe obesity and over 40 morbid obesity) and evaluated in relation to different types of postoperative complications. Results: According to the data obtained in our series, the most common surgical complication was dehiscence of the surgical scar, occurring in $80.5 \%$ of overweight women (BMI>25), followed by hematoma, diagnosed in 72 patients, $59.7 \%$ overweight women. The third most common complication was infection of the surgical site in only 19 patients $(0.3 \%)$, with $78.9 \%$ in overweight women. This fact can be explained by inadequate perfusion, deficiency of macro and micronutrients and hypoxia that impairs collagen synthesis, resulting in poor healing, causing dehiscence. From these data presented, it is possible to infer thatcomplications such as seroma, hematoma, infection of the surgical wound, dehiscence, and even loss of the surgical flap are strongly associated with increased body weight. Conclusions: We came to the conclusion that the increase in body weight, especially in patients with a BMI> 25, is an unfavorable factor for the occurrence of surgical complications in patients with breast cancer, and it is essential to provide guidance on the risks of complications in the preoperative evaluation for adjusting the best surgical procedure and mainly for considering late reconstruction. 